This item was submitted to Loughborough's Research Repository by the author.

Items in Figshare are protected by copyright, with all rights reserved, unless otherwise indicated.

\title{
Effects of spectrum on the power rating of amorphous silicon photovoltaic devices
}

PLEASE CITE THE PUBLISHED VERSION

http://dx.doi.org/10.1002/pip.1080

\section{PUBLISHER}

(c) 2011 John Wiley \& Sons, Ltd.

\section{VERSION}

AM (Accepted Manuscript)

\section{PUBLISHER STATEMENT}

This work is made available according to the conditions of the Creative Commons Attribution-NonCommercialNoDerivatives 4.0 International (CC BY-NC-ND 4.0) licence. Full details of this licence are available at: https://creativecommons.org/licenses/by-nc-nd/4.0/

\section{LICENCE}

CC BY-NC-ND 4.0

\section{REPOSITORY RECORD}

Monokroussos, Christos, Martin Bliss, Yingning Qiu, Christopher J. Hibberd, Thomas R. Betts, A.N. Tiwari, and Ralph Gottschalg. 2019. "Effects of Spectrum on the Power Rating of Amorphous Silicon Photovoltaic Devices”. figshare. https://hdl.handle.net/2134/17799. 


\title{
Effects of spectrum on the power rating of amorphous silicon photovoltaic devices
}

\author{
C. Monokroussos ${ }^{1}$, M. Bliss ${ }^{1}$, Y. N. Qiu ${ }^{1}$, C. J. Hibberd ${ }^{1}$, T. R. Betts ${ }^{1}$, A. N. Tiwari ${ }^{2}$ \\ and R. Gottschalg ${ }^{1}$
}

${ }^{1}$ Centre for Renewable Energy Systems Technology (CREST),

Department of Electronic and Electrical Engineering, Loughborough University, Loughborough, Leicestershire, LE11 3TU, UK

${ }^{2}$ Laboratory for Thin-Films and Photovoltaics, EMPA, CH-8600

Duebendorf, Switzerland

E-mail address: C.Monokroussos@lboro.ac.uk

\begin{abstract}
The effects of different spectra on the laboratory based performance evaluation of amorphous silicon solar cells is investigated using an opto-electrical model which was developed specifically for this purpose. The aim is to quantify uncertainties in the calibration process. Two main uncertainties arise from the differences in the test spectrum and the standard spectrum. First, the mismatch between reference cells and the measured device, which is shown to be voltage dependent in the case of amorphous silicon devices. Second, the fill factor of the device is affected by different spectra. Different cell structures and states (specifically different i-layer thickness and levels of degradation) for the different light sources are investigated in this work. These sources are different solar simulators, LED sources, Tungsten as well as the standard terrestrial AM1.5G radiation. It is shown that the performance cannot be evaluated by short circuit current alone. The voltage dependent quantum efficiency of $p$-i-n devices can introduce a mismatch in the PMPP of $1 \%$ for $250 \mathrm{~nm}$ i-layer devices in as prepared state, rising to up to $4 \%$ for the $600 \mathrm{~nm}$ i-layer devices at degraded state.
\end{abstract}

\section{Introduction}

The power rating of photovoltaic devices typically determines the value of the product and thus is of utmost importance in the value chain. It is typically determined by a solar simulator measurement. The spectrum of these solar simulators should resemble the standard terrestrial AM1.5G radiation [1,2]. In reality, though, their spectrum deviates significantly from this standard. The deviations can be in the range of $\pm 25 \%$ in a given spectral band and still meet the highest classification of solar simulators [3]. The difference for solar spectrum is normally accounted for by carrying out a spectral mismatch correction [4], which works well for correcting current differences. However, it has been shown $[5,6]$ that there is a secondary effect on the fill factor for amorphous silicon (a-Si) devices, which is generally not considered and introduces an uncertainty into the measurement process. This effect has been attributed to the voltage dependence of the quantum efficiency of amorphous silicon photovoltaic devices [5]. The aim of this work is to better understand and quantify this uncertainty for the different measurement systems being used today. In production, this is normally accounted for by calibrating the solar simulator, which works well as long as the assumption holds that all devices are identical in terms of material and device characteristics. This will not be the case, if the state of the material is unknown or changing, as demonstrated 
below and experienced by test laboratories or measurements carried out to verify that the devices are still within their guaranteed power rating.

Recently, the use of light-emitting diodes (LEDs) as solar cell testers ${ }^{1}$ has also been reported [7-9], some based on a single colour LEDs only. This is especially true for red LED single solar testers, which are currently entering the market. Consequently, test houses should be aware of the performance deviations that may arise. It will be shown in this paper that this may increase the uncertainties further if not implemented carefully. This paper quantifies the effects of voltage dependent quantum efficiency on typical measurements of a-Si:H cell technologies, and illustrates the effects of different device states.

In order to quantify these uncertainties, one needs to model the specifics of a-Si devices with respect to the device structure. This is a p-i-n junction rather than the common p$\mathrm{n}$ junction and is affected by wavelength dependent generation of electron-hole pairs and the effects of dangling-bond recombination. This requires a simulation of the optoelectrical behaviour of the device, as optical absorption as well as electrical generation have an impact on the device performance here. The model developed for this work is reviewed in section 2 .

In section 3 the performance of a-Si:H cells of varying i-layer thickness and level of degradation under different excitation spectra is probed. The i-layer thicknesses investigated here $(250-400 \mathrm{~nm})$, reflect the size that is currently considered by R\&D standards. A device with thicker i-layer is also examined $(600 \mathrm{~nm})$, mainly because there are still a number of manufacturers, which produce thicker devices. Therefore, the need to rate devices with increased i-layer thickness by test houses still remains a reality. The selected illumination spectra include those of class A, B and C solar simulators, LEDs, Tungsten and the standard terrestrial AM1.5G radiation spectrum [2]. A difficulty in calibrating a-Si:H cell technologies is the change of material properties due to degradation after light soaking [10] or annealing due to high operating temperatures [11]. Cell calibration uncertainty is examined here in combination with different levels of degradation and i-layer thickness because both are expected to have a strong influence the calibration accuracy. The investigation shows that the performance of the cells depends on the light source, but also the device state.

The effects of different light sources on calibration and the mismatch factor are examined on section 4. It will be shown that the accuracy of performance evaluation of a-Si solar cells can be enhanced by not only taking into account the spectral correction factor at $0 \mathrm{~V}$, but also its voltage dependence. The magnitude of required corrections of the calibration varies for different device structures and levels of degradation, as it depends on the physics of the devices.

\section{Modelling Aspects}

\footnotetext{
${ }^{1}$ Most devices do not meet the criteria set out in international standards [IEC60904-9] for solar simulators, hence the use of the term solar tester.
} 
This section presents the theoretical background of the opto-electrical model used in the simulations. First, the optical model is described and then the electrical simulations are detailed. A more thorough presentation of the model, as well as its validation, which has been developed at CREST, Loughborough University, can be found in literature [12].

\subsection{Optical Model}

The approach adopted in this work is based on a ray tracing method [13] allowing the calculation of generation profiles of multi-layer structures such as thin film silicon devices. The optical model is a two-dimensional model treating light as propagating electromagnetic radiation. Incoherence is assumed, i.e. no interference effects will be assumed here. This is the case for solar natural light, which is incoherent light of random polarisation. The model takes into account two different cases of light: scattered and non-scattered for plane and rough interfaces. This model is based on the approaches proposed by Prentice [14], Krc et al. [15] and Springer et al. [16]. However, the geometry of these models is one-dimensional, while the suggested model extends the geometry to two dimensions allowing the calculation of oblique photon paths within the solar cell structure. Light scattering at rough interfaces has been implemented as defined by the scalar scattering theory; reducing the Fresnel's coefficients by the scattering factors [17].

\subsection{Electrical Model}

In order to simulate the performance variations of amorphous silicon solar cells under different illumination spectra, one also needs to model their electrical behaviour. The model used for this purpose is based on the numerical solution of continuity, Poisson and current density equations. The distortions of the electric field caused by various defect density profiles are taken into account. For the purposes of the numerical solution a modified Gummel-Schrafetter scheme was adapted [18-19].

Amorphous silicon devices require a modification of the classic SRH recombination. The specific recombination mechanism in a-Si solar cells is dangling bond driven recombination, which dominates the process [21]. Hack and Shur [22] have shown cell performance is primarily limited by hole transport properties, which is related to the amphoteric nature of these defects, i.e. recombination occurs via two parallel paths of $\mathrm{D}^{+} / \mathrm{D}^{0}$ and $\mathrm{D}^{0} / \mathrm{D}^{-}$. Here $\mathrm{D}^{+}, \mathrm{D}^{-}$and $\mathrm{D}^{0}$ are the positively, negatively and neutrally charged dangling bonds.

\subsection{Model Parameters}

In this section, the opto-electrical modelling scheme described in 2.1 and 2.2 is used to describe the behaviour of solar cells of three different i-layer thicknesses, $250 \mathrm{~nm}$, $400 \mathrm{~nm}$ and $600 \mathrm{~nm}$, at as prepared and degraded state in terms of quantum efficiency (QE) and current density-voltage (J-V) characteristics. The input parameters for the simulations are summarised in Table I. The chosen input parameters commonly used in the literature [23-25]. Therefore the results shown here should be of general applicability. 
Initially, the studied structures of $250 \mathrm{~nm}, 400 \mathrm{~nm}$ and $600 \mathrm{~nm}$ i-layer thickness are optically analysed. The simulated multilayer structure consists of $1 \mathrm{~mm}$ Glass/500nm $\mathrm{ZnO}$ TCO layer/7nm $\mu \mathrm{c}-\mathrm{Si}$ p-layer/a-Si:H i-layer/10nm $\mu \mathrm{c}-\mathrm{Si}$ n-layer/400nm: ZnOAg buffer layer-back reflector. The thickness of the $\mathrm{ZnO}$ layer at the $\mathrm{ZnO} / \mathrm{Ag}$ back reflector is $90 \mathrm{~nm}$. The distribution of light absorption for the case of the $600 \mathrm{~nm}$ i-layer cell is shown in figure 1. It should be noted that the peak shown in the region of $720-740 \mathrm{~nm}$ is an artefact of the measured absorption coefficients used in this work. In the next step the generation profiles are calculated. They are used to simulate the electrical behaviour of the cells.

Table I: List of properties used for electrical simulations

\begin{tabular}{ll}
\hline Property & Value \\
\hline a-Si:H dielectric constant & $11.9[23]$ \\
p-layer doping & $10^{18} \mathrm{~cm}^{-3}$ \\
n-layer doping & $10^{18} \mathrm{~cm}^{-3}$ \\
a-Si:H thermal velocity & $210^{7} \mathrm{~cm}^{\mathrm{s}}[24]$ \\
i-layer dangling bond density & $1-7 \cdot 10^{15} \mathrm{~cm}^{-3}[24]$ \\
$\mu_{\mathrm{p}} / \mu_{\mathrm{p}}$ & $10[25]$ \\
$\tau^{0} / \tau^{+}, \tau^{0} / \tau^{-}$ & $500[24]$ \\
$\tau_{\mathrm{n}}{ }^{0} / \tau_{\mathrm{p}}{ }^{0}$ & $20[24]$ \\
Surface recombination & \\
velocity, $\mathrm{S}_{\mathrm{p}}$ & $10^{6} \mathrm{~cm} \mathrm{~s}^{-1}$ \\
$\begin{array}{l}\text { Surface recombination } \\
\text { velocity, } \mathrm{S}_{\mathrm{n}}\end{array}$ & $510^{3} \mathrm{~cm} \mathrm{~s}^{-1}$ \\
$\begin{array}{l}\text { Parasitic series } \\
\text { sheet resistance }\end{array}$ & \\
$\begin{array}{l}\text { Parasitic parallel } \\
\text { sheet resistance }\end{array}$ & $2 \Omega \mathrm{cm}^{2}$ \\
\end{tabular}

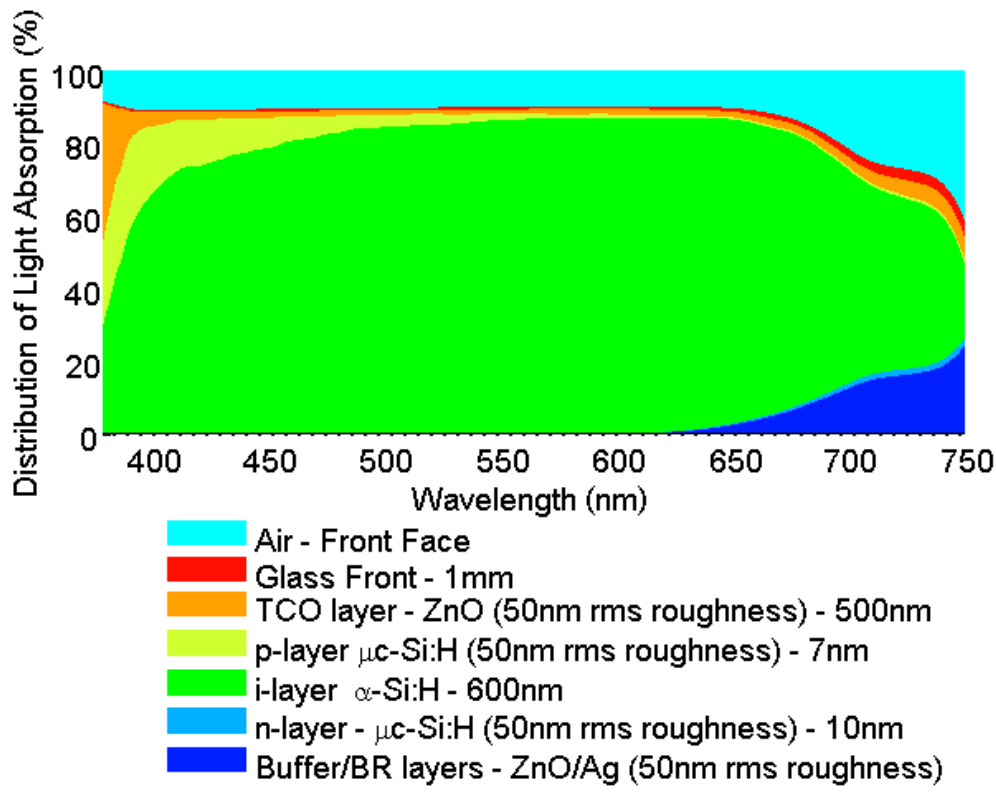

Figure 1. Distribution of light absorption in different layers of a-Si:H p-i-n solar cells for three a cells of $600 \mathrm{~nm}$ i-layer thickness. 
The contribution of the generation profile is analysed and converted into collected charge carriers, i.e. quantum efficiency and $\mathrm{J}-\mathrm{V}$ characteristics. The temperature has been set to equal the standard test condition's (STC) temperature of $25^{\circ} \mathrm{C}$ [2]. Temperature variations are not considered here, as the focus is on laboratory measurements and temperatures are controllable within such an environment. The quantum efficiency in this examination is the external quantum efficiency (EQE). This is defined as the probability that a photon of energy hc/ $\lambda$ will be converted to supply an electron to the cell terminal. The modelled $\mathrm{J}-\mathrm{V}$ characteristics are shown in figure $2, \mathrm{~b}$. The as prepared state refers to simulated cells of dangling bond density $10^{15} \mathrm{~cm}^{-3}$ and the degraded state to $710^{15} \mathrm{~cm}^{-3}$, as light-soaking is known to increase the defect density of the i-layer [26] and cause a degradation of their performance. The degraded state presented here is an approximation of the stabilised state. The cell efficiencies are reduced by $20-30 \%$ comparing to the as-prepared state. The use of stabilised value is very much focussed on laboratory ageing, while in realistic conditions the behaviour is much more variable with continuous degradation and annealing. Thus the degraded state here approximates the worst operating point during the course of a year. The value of degradation is in agreement with both experimental measurements [26, 27] and theoretical calculations [28], which approximate the magnitude of degradation in a-Si:H solar cells.
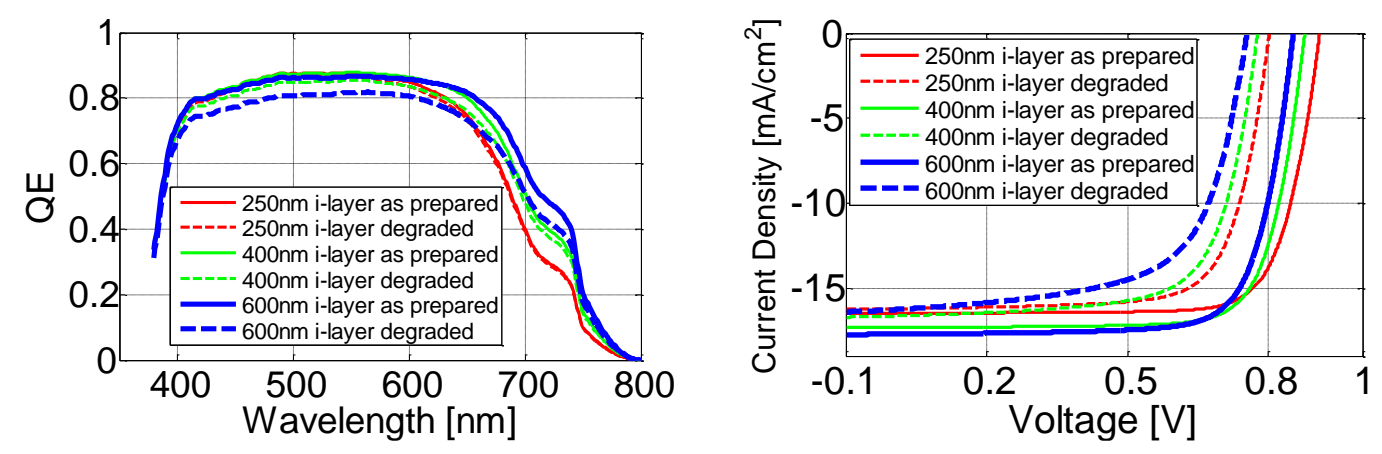

Figure 2. Modelled quantum efficiency curves at $0 \mathrm{~V}$ at as prepared and degraded state (a) and modelled $\mathrm{J}-\mathrm{V}$ characteristics (b). The excitation spectrum in this case is the standard terrestrial AM1.5G irradiance.

\section{Effects of Different Measurement Spectra on the Performance of a-Si:H Solar Cells' Performance}

As outlined above, there are indications that different spectra have different effects on a-Si device performance [6] which goes beyond that of a simple mismatch correction given in the standards [29]. This is demonstrated here using two very extreme spectra, two different LEDs, a blue $(\lambda=445 \mathrm{~nm})$ and a red $(\lambda=640 \mathrm{~nm})$ and also a number of illumination spectra typically used for measuring a-Si devices in the different laboratories. The selected spectra are of commercially available solar simulators of spectral classes A, B and C as defined in the appropriate international standard [30]. 
The standard reference spectrum AM1.5G is taken as defined in [2]. Also included is the spectrum of a tungsten halogen light, as these are also used in some laboratories to characterise photovoltaic devices. Tungsten and LED spectra may be inappropriate for the purpose of simulating the standard terrestrial spectrum, but they are used in some instances nevertheless. The comparison of the normalized to spectral irradiance spectra in 380-800nm region is given in figure 3.

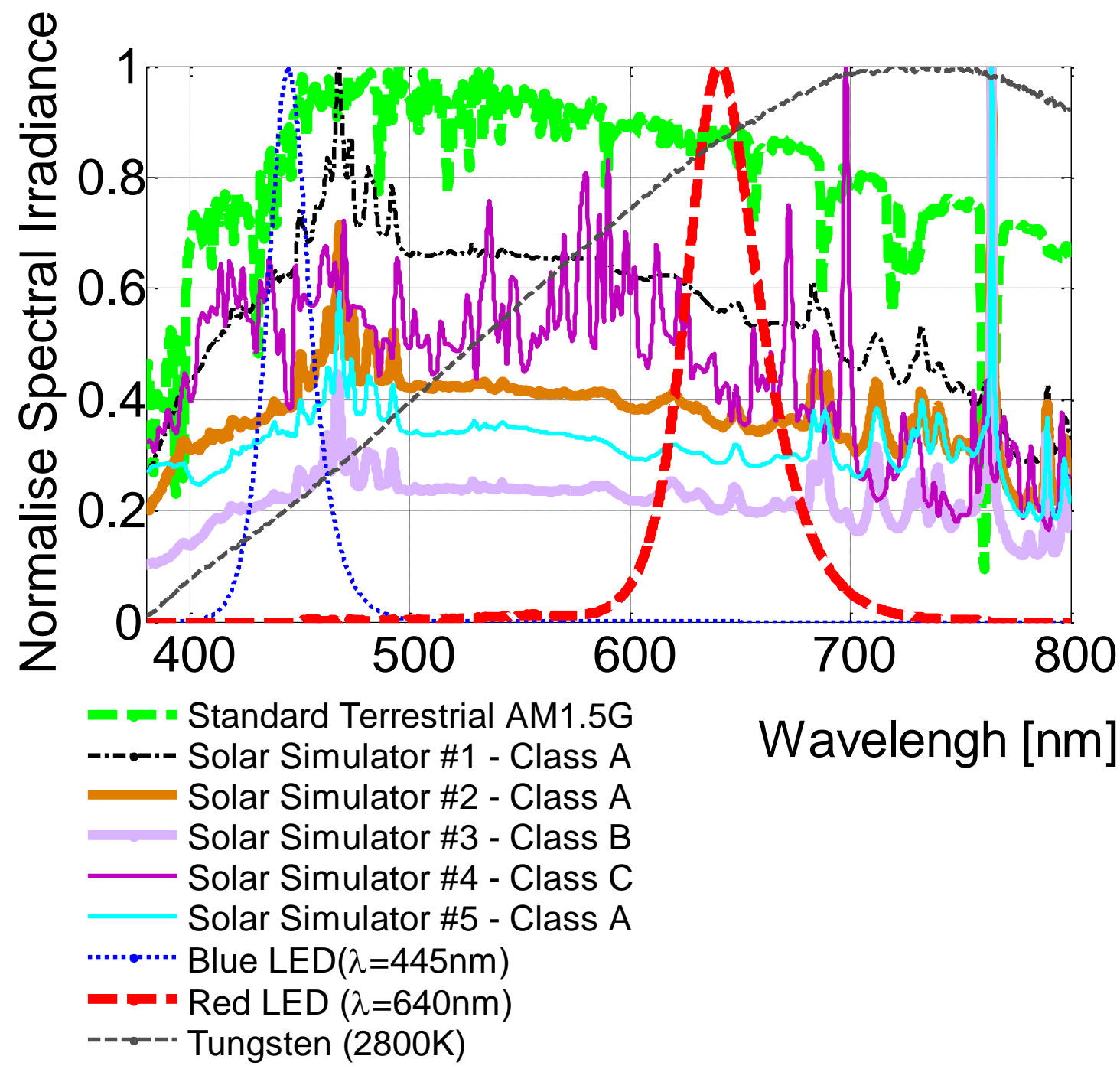

Figure 3. Comparison of normalized spectra $(380-800 \mathrm{~nm})$ used in the simulations. The illumination profiles shown here vary from typical solar simulator spectra to extreme LED spectra.

It is useful to have a single number to compare different spectra. The average photon energy (APE) number, as defined by Betts et al. [31], is such a tool. Characterising spectra with their APE may simplify spectral differences and may not reflect all features seen in indoor calibrations. A comparison of the used spectra in terms of APE and its standard deviation is given in Table II. It should be noted that the solar simulator spectra 
correspond to outdoor spectra with an air mass of 3-10 [32], i.e. spectra produced by today's solar simulators are very different to what is seen in reality.

Table II: Average photon energy and its standard deviation for each spectrum at $380-800 \mathrm{~nm}$ wavelength region.

\begin{tabular}{|c|c|c|c|}
\hline Spectrum & $\begin{array}{l}\text { I Simulator } \\
\text { Class }\end{array}$ & $\begin{array}{l}\mathrm{APE} \\
{[\mathrm{eV}] \mathrm{I}}\end{array}$ & $\begin{array}{c}\text { Standard } \\
\text { Deviation }[\mathrm{eV}]\end{array}$ \\
\hline AM1.5G [2] & - & 2.1389 & 0.356 \\
\hline Solar Simulator 1 & A & 2.1650 & 0.365 \\
\hline Solar Simulator 2 & A & 2.1487 & 0.359 \\
\hline Solar Simulator 3 & B & 2.1279 & 0.363 \\
\hline Solar Simulator 4 & $\mathrm{C}$ & 2.2182 & 0.364 \\
\hline Solar Simulator 5 & $\mathrm{~A}$ & 2.1533 & 0.381 \\
\hline Blue LED & - & 2.7784 & 0.061 \\
\hline Red LED & - & 1.9267 & 0.054 \\
\hline Tungsten & - & 1.9070 & 0.229 \\
\hline
\end{tabular}

In the following the magnitude of secondary effects on the calibration accuracy are discussed. The selected spectra are used as an input for the model and the J-V curves of typical cells are modelled. The intensities of the spectra were calibrated to produce the same current as determined by quantum efficiency measurements, as they would be produced by the AM1.5G spectrum. This essentially simulates the spectral mismatch correction [4] and ensures that the results reported here are purely the effects caused by the differences in the underlying physical attributes of the devices.

Figure 4 shows small, but noticeable changes in the performance parameters of the same devices under different excitation spectra. These changes can be attributed to the voltage dependence of the quantum efficiency; the quantified explanation is given in the next section. It is also shown that high class solar simulators realistically do not suffer from secondary effects and effects in the measurement calibration will dominate. The introduced errors do not exceed $0.3 \%$ for the power output and fill factor (FF). It is shown that red shifted spectra, e.g. the Tungsten-Halogen or the red LED underestimate performance parameters much more significantly, with errors exceeding $1.5 \%$. Spectra which have a blue-shift, like the blue LED, will overestimate device performance. Degradation has a considerable effect on measurement uncertainty, as the deviations were doubled in most cases. The thickness of the i-layer did not affect the measurement uncertainty significantly under the examined solar simulator spectra. 
250nm i-layer @ as prepared state Matching $\mathrm{J}_{\mathrm{sc}}$ condition

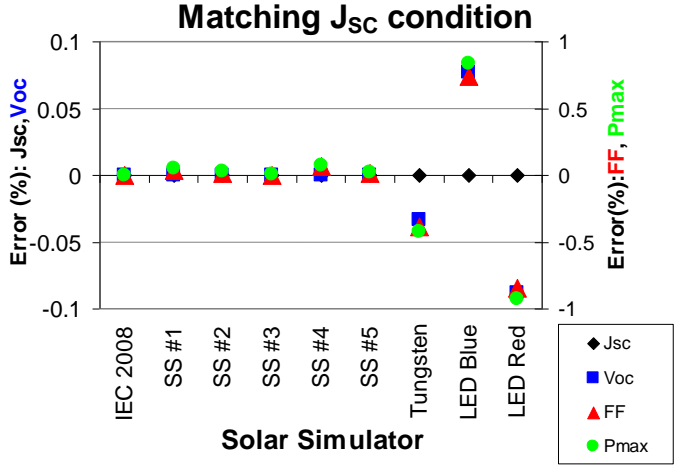

400nm i-layer @ as prepared state Matching $\mathrm{J}_{\mathrm{SC}}$ condition

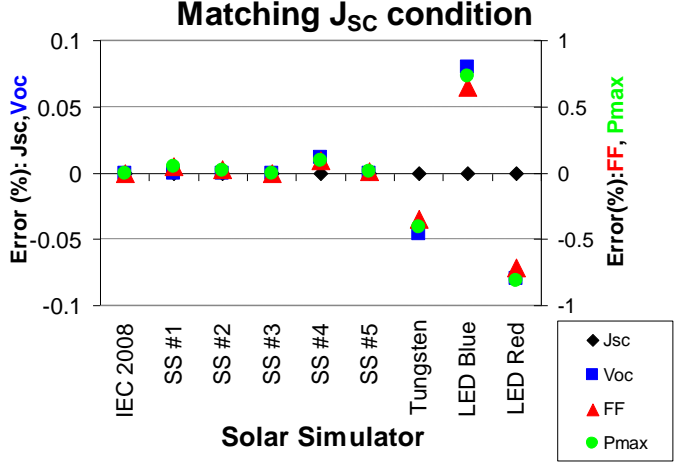

600nm i-layer @ as prepared state Matching $\mathrm{J}_{\mathrm{sc}}$ condition

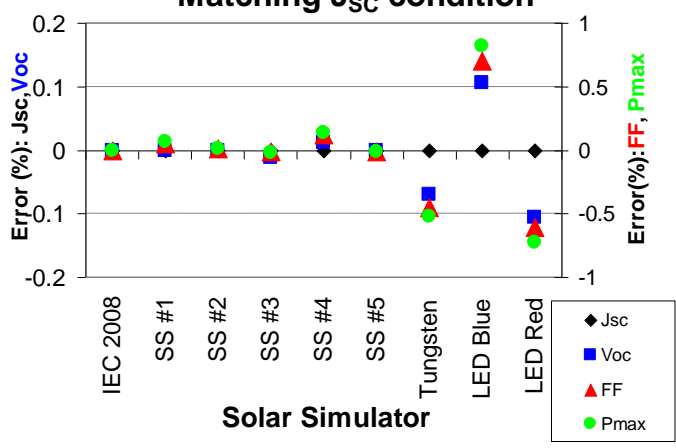

250nm i-layer@ degraded state

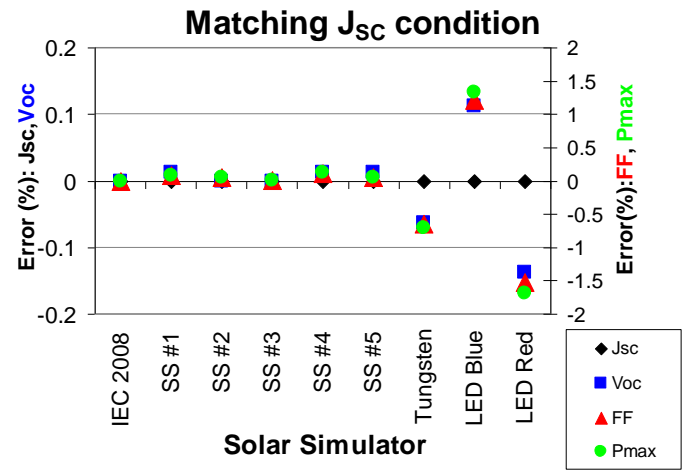

400nm i-layer @ degraded state Matching $\mathrm{J}_{\mathrm{sC}}$ condition

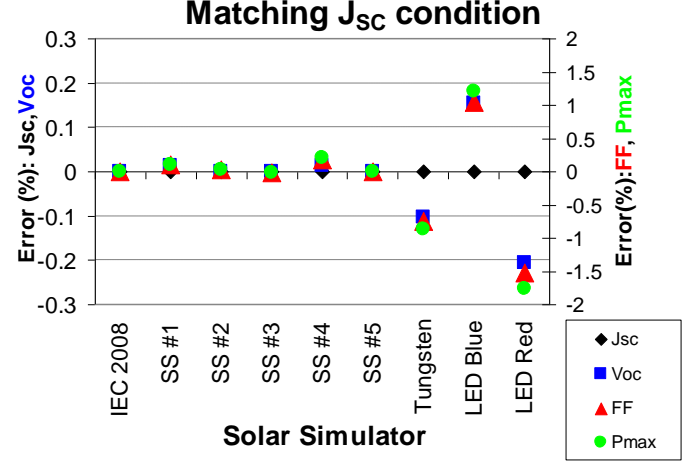

600nm i-layer@ degraded state Matching $\mathrm{J}_{\mathrm{sc}}$ condition

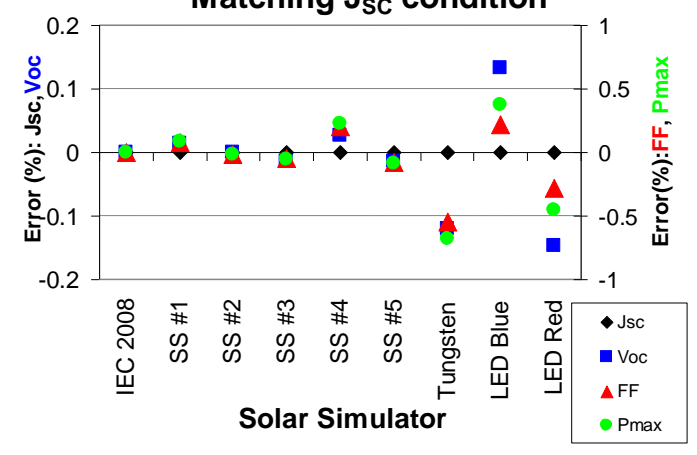

Figure 4. Difference of the performance parameters under different excitation spectra to STC performance parameters for cells of 250, 400 and 600nm i-layer thickness in as prepared and degraded state. In all cases the $\mathrm{J}-\mathrm{V}$ curves were calibrated to match JSC of standard test conditions.

In order to separate the wavelength dependency of the effects examination of strictly monochromatic excitation spectra is required as shown in figure 5. For the purpose of the simulations 40 strictly monochromatic light sources in the range of $390 \mathrm{~nm}$ to $780 \mathrm{~nm}$ were examined; again at matching current under short-circuit condition. It is shown here, that there exists a correlation among the magnitude of the errors with i-layer thickness, degradation and photon energy. For the case of the $400 \mathrm{~nm}$ i-layer aSi:H cell in degraded state, its performance is overestimated for blue light sources $(400-500 \mathrm{~nm})$. The overestimation is increasing and reaching its peak in the green-yellow region $(550 \mathrm{~nm})$. The deviation progressively decreases in the yellow-orange region (550$600 \mathrm{~nm}$ ) until it becomes negligible. Performance is progressively underestimated in the 
orange $(600-640 \mathrm{~nm})$, red $(640-700 \mathrm{~nm})$ and infra-red regions $(700-750 \mathrm{~nm})$. A similar trend is observed for all cells. However, the range of the overestimation and underestimation varies with i-layer thickness and degradation state. Furthermore, thicker i-layer devices are prone to higher maximum deviations. The level of degradation has also a strong effect on the observed deviations. Increased degradation resulted in higher maximum deviations, as shown here for the 600nm cell (Figure 5, c and $\mathrm{d}$ ). The wavelength of the maximum deviation is consistently increasing with increasing i-layer thickness, as is the effect of degradation. Another point of interest is the existence of a monochromatic excitation where all key performance parameters $\left(\mathrm{J}_{\mathrm{SC}}\right.$, MPP and $\mathrm{V}_{\mathrm{OC}}$ ) resemble continuous chromatic STC excitation. In addition, the simulations have shown that the FF reaches its maximum value at a shorter wavelength than the wavelength, which resembles best the performance of STC excitation. The latter is the reason many researchers, such as Rüther et al. [6], Gottschalg el al. [33] and Minemoto et al. [34], who have studied the outdoor performance of solar cells have reported "bluer" spectra to be beneficial for the FF. Strictly speaking "bluer" spectra are beneficial for performance in terms of the FF, but not necessarily higher APE spectra will have higher FF, as the peak is located in the yellow-green region.
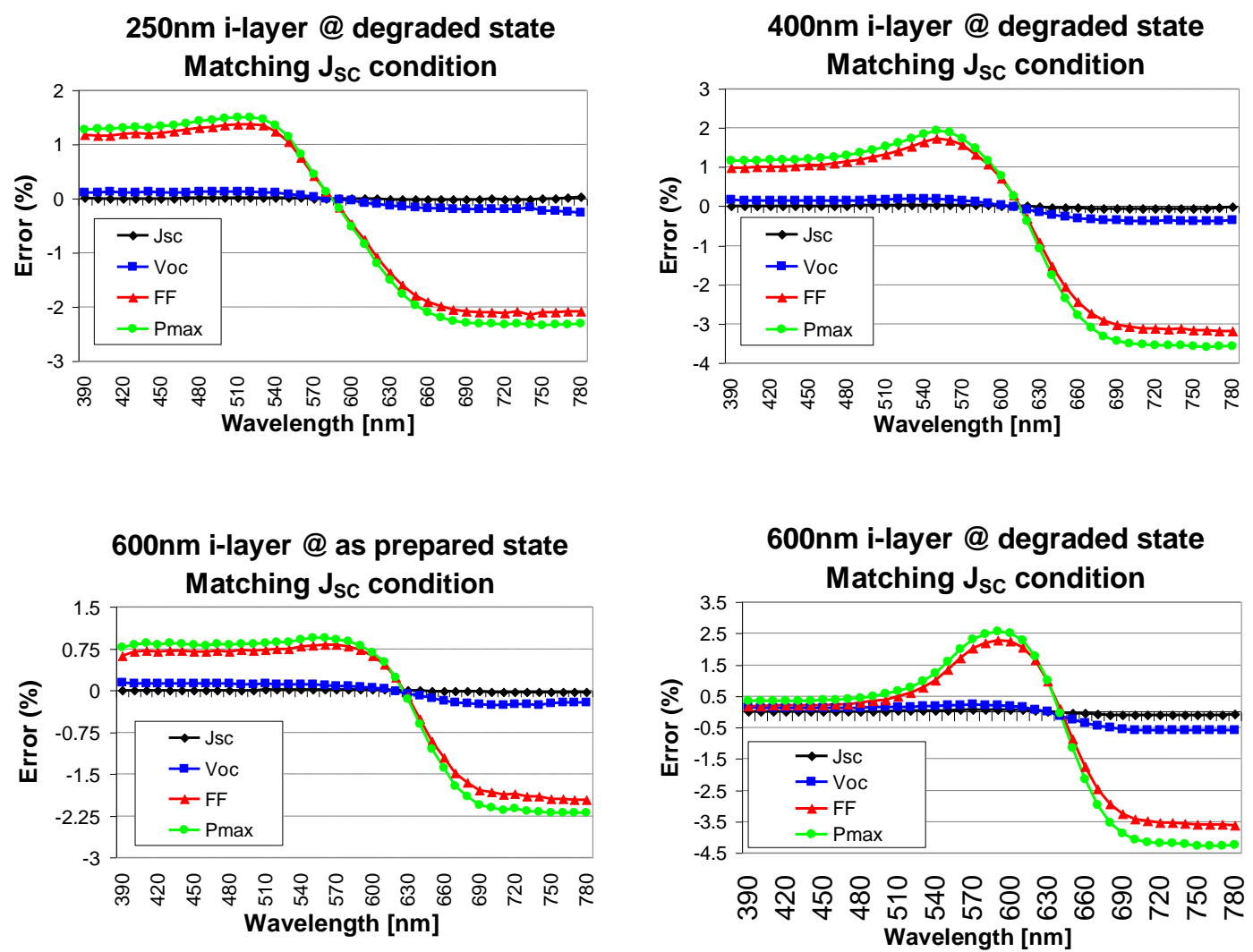

Figure 5. Difference of the performance parameters under monochromatic excitation spectra (x-axis) to the parameters under standard test conditions of the cells of 250, 400 and $600 \mathrm{~nm}$ i-layer thickness in degraded state (a, b and d). The as prepared state (c) is shown here only for the $600 \mathrm{~nm}$ i-layer cell. In all cases the J-V curves were calibrated to match JSC of standard test conditions. 


\section{Effects of voltage dependence quantum efficiency on device calibration}

It was shown above that there are noticeable variations in the performance parameters of a-Si:H solar cells. This can be explained in terms of voltage dependent quantum efficiency, which is discussed in this section. Increasing bias will cause a progressive collapse of the internal electric field within the i-layer. This results in a decrease of the electron-hole collection at the terminals of the device and can be interpreted as a change in the voltage-dependent quantum efficiency (Figure 6). The partial collection efficiency $\mathrm{q}=\mathrm{EQE}(\mathrm{V}, \lambda) / \mathrm{EQE}(-1 \mathrm{~V}, \lambda)$, has previously been defined as a useful quantity for investigating the voltage dependent chromatic dispersion of a-Si devices [5] and is used here for the same purpose (Figure 7). It is shown that longer wavelengths are prone to stronger quantum efficiency changes with increasing bias, which towards higher operation voltages yields a shift of the QE peak towards shorter wavelengths [35]. As a result a voltage dependent mismatch correction is necessary to calibrate for given spectra. The effects of this are discussed below.

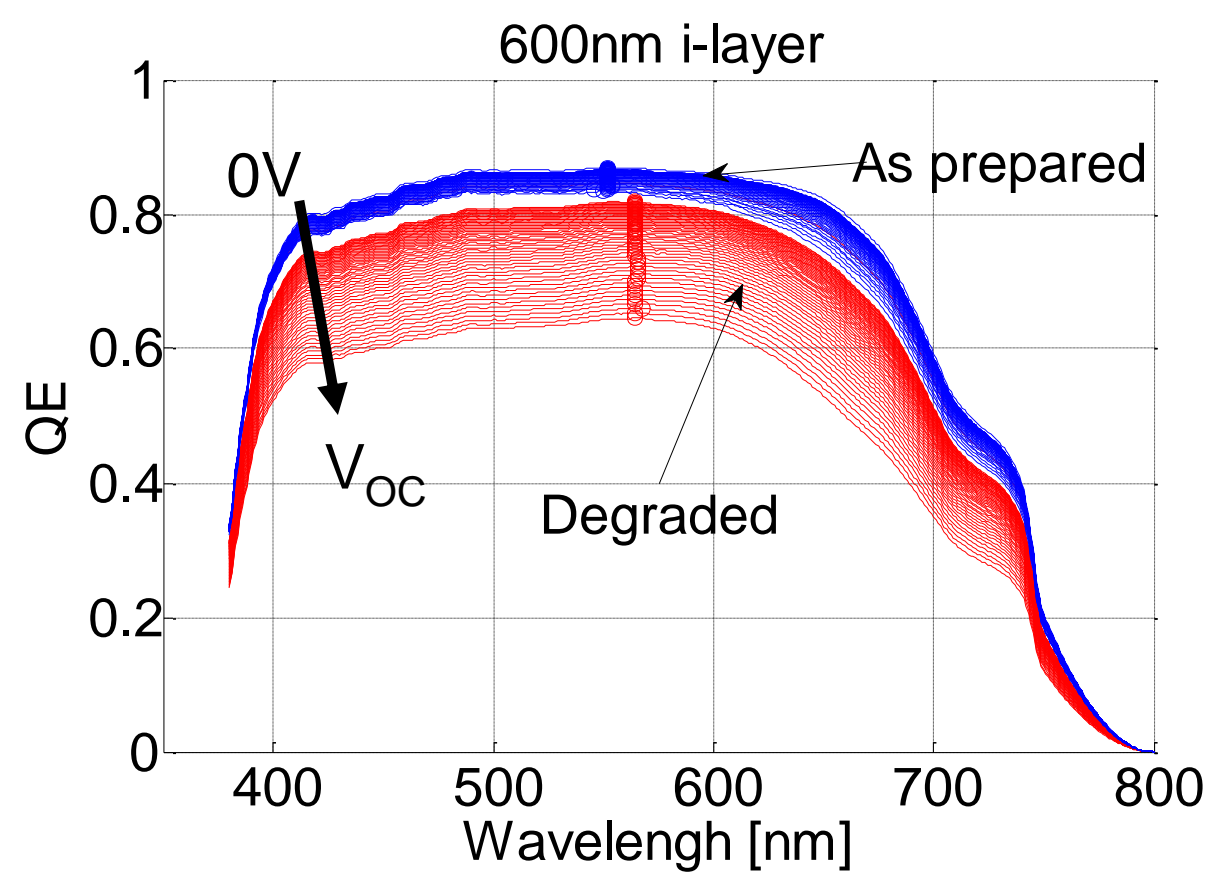

Figure 6. Simulation results for the voltage dependence of the efficiency shown here for the case of the $600 \mathrm{~nm}$ i-layer cell. 


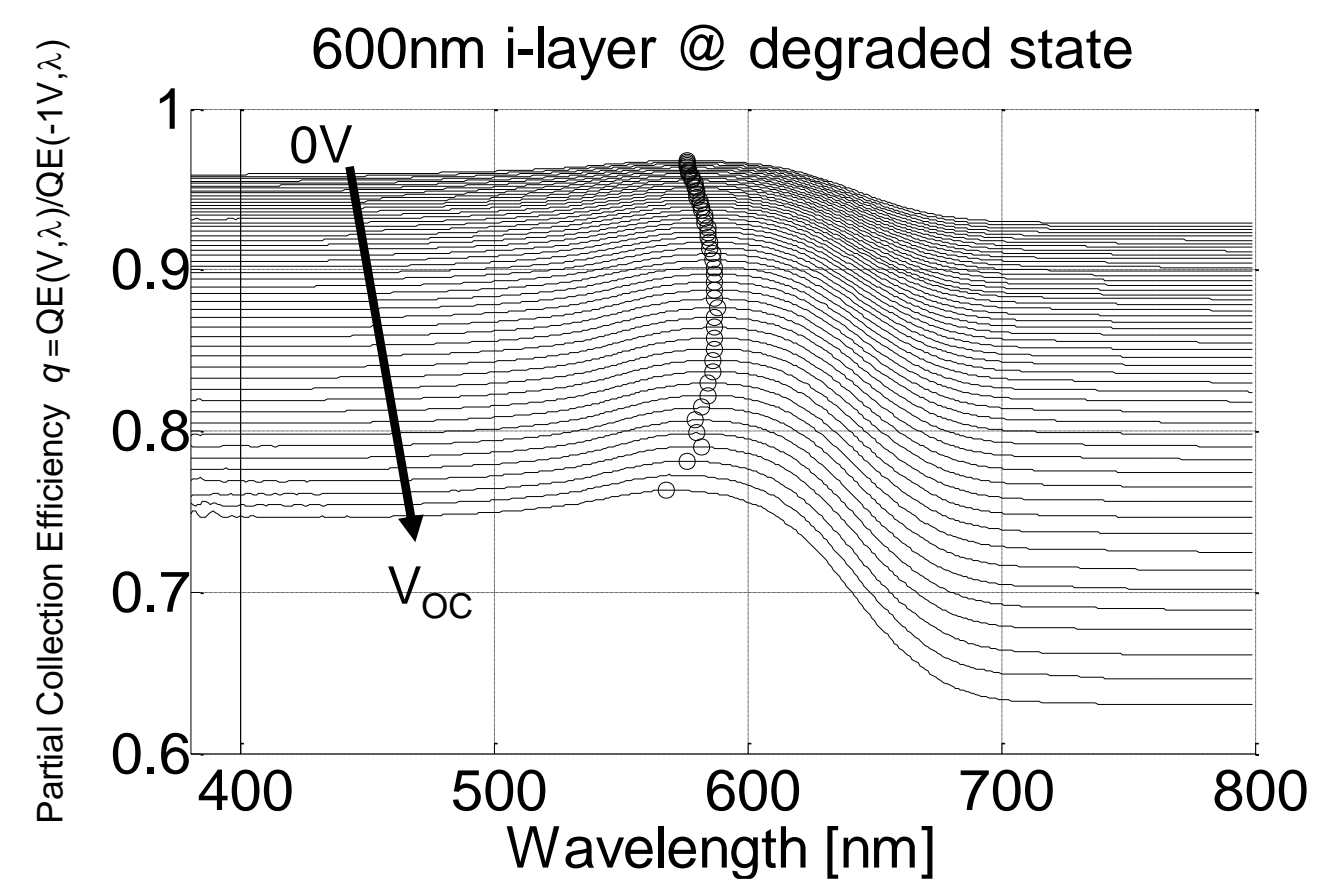

Figure 7. The partial collection efficiency is a useful quantity visualizing the change of $\mathrm{QE}(\mathrm{V}, 1)$ with voltage shown here for the $600 \mathrm{~nm}$ i-layer cell at the degraded state.

\subsection{Spectral correction factor}

The spectral correction factor, $\mathrm{M}$, is formulated to correct differences between test and standard spectrum, essentially by correcting the short circuit current of a the device to what it should be at the reference spectrum and assuming the principle of superposition for the cell behaviour. It is typically given as [36].

$$
M=\frac{\int_{\lambda_{1}}^{\lambda_{2}} E_{s}(\lambda) S_{t}(\lambda) d \lambda \cdot \int_{\lambda_{1}}^{\lambda_{2}} E_{\text {ref }}(\lambda) S_{r}(\lambda) d \lambda}{\int_{\lambda_{1}}^{\lambda_{2}} E_{s}(\lambda) S_{r}(\lambda) d \lambda \cdot \int_{\lambda_{1}}^{\lambda_{2}} E_{\text {ref }}(\lambda) S_{t}(\lambda) d \lambda}
$$

Dividing the measured photocurrent by the spectral mismatch correction factor reduces the error in the photocurrent when measuring a solar cell under a light source $\mathrm{E}_{\mathrm{s}}(\lambda)$ in respect to a reference spectrum $\mathrm{E}_{\mathrm{ref}}(\lambda)$. The integration limits $\lambda_{1}$ and $\lambda_{2}$ should be the same for all integrals and are limited by the responsivity ranges of the test cell $S_{t}(\lambda)$ and the reference cell $\mathrm{S}_{\mathrm{r}}(\lambda)$, which in the case of a-Si:H solar cells varies between $380 \mathrm{~nm}$ and $800 \mathrm{~nm}$.

\subsection{Voltage-dependence of the spectral correction factor $M$}

The impact of different light sources under different forward bias conditions on the spectral correction factor $\mathrm{M}$ is investigated. For this purpose the responsivity of the device at $0 \mathrm{~V}$ bias is assumed to be the "reference cell", and its spectral response under different forward bias conditions the "test cells" probing propagation of deviations in 
the performance. Using the expression (1) with the illumination spectra shown in figure 3 , and the calculated voltage-dependent responsivity, one can estimate the voltagedependent spectral mismatch factor $\mathrm{M}$. The results of the calculations are shown in figure 8 for the case of the 400nm i-layer cell in the as prepared and degraded state. It is shown that the deviation heavily depends on the solar simulator light source, specifically sources which deviate strongly to standard terrestrial AM1.5G radiation. Although there are minimal errors for all light sources up to $70 \%$ of $\mathrm{V}_{\mathrm{OC}}$, the errors are gradually increasing from $70 \%$ of $\mathrm{V}_{\mathrm{OC}}$ to deviate strongly and become noticeable above $80 \%$ of the $\mathrm{V}_{\mathrm{OC}}$, even for class A solar simulators. This is typically in the region of the maximum power point. As it was already outlined above, the mismatch factor deviation becomes stronger with increasing i-layer thickness and degradation, regardless the light source.
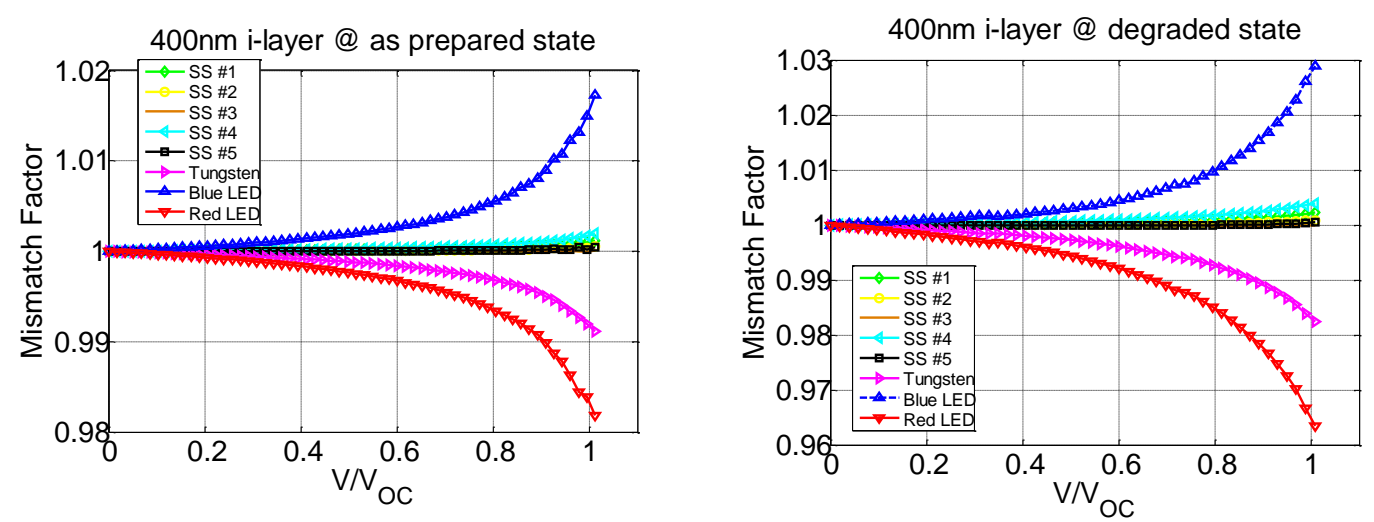

Figure 8. Variation of the mismatch factor $M$ for the case of the $400 \mathrm{~nm}$ cell in the as prepared (a) and degraded (b) state. The X-axis represents here the voltage normalized by the $V_{O C}$ value of the cell under STCs.

\section{Conclusions}

In this work the effects of different solar simulator light sources on the evaluation of indoor performance of a-Si:H solar cells have been examined. The behaviour of aSi:H solar cells was analysed using opto-electrical modelling. Three cells of $250 \mathrm{~nm}, 400 \mathrm{~nm}$ and $600 \mathrm{nmm}$ i-layer thickness in as prepared and degraded state were used to evaluate the performance. Different light sources are used for excitation. It is shown that different light sources result in deviations in the performance evaluation of cells. These deviations are usually small for class A solar simulators, but may be significant for Halogen or LED sources.

These deviations are due to the voltage dependence of the quantum efficiency, which affects different wavelengths differently. This means in practical terms that one should not test a-Si with red LED flasher devices being on the market. This would introduce uncertainties as it depends on material quality. It is even less suitable for aged materials.

It was also shown in this paper that the device state affects the magnitude of these spectral effects, as errors seem to be dependent on the level of degradation, but also the 
i-layer thickness of the a-Si:H device. This voltage dependence of the spectral response implies that the mismatch correction should be carried out on a point by point basis for unknown a-Si devices. Amorphous silicon devices in a known state can be corrected by 'calibrating' the solar simulator ${ }^{2}$, i.e. introducing rather arbitrary correction factors that then reproduce the measurements of a reference module being tested at reference laboratories. The situation will be significantly more complicated for multi-junctions. Here the fill factor would also be affected by the relative matching of the cells, with typically the minimum of the FF being for optimally matched devices [37]. This matching might change with material state and in extreme cases might result in different junctions limiting the performance. Thus the fill factor variation will be less predictable for multi-junctions and a point by point correction is absolutely necessary. This would require measuring the QE certainly for points around the MPP and calculating the variation of MMF. In the case of multi-junctions this would involve a junction-byjunction measurement as well.

A point-by-point mismatch correction would remove the need for a 'calibration' of the solar simulator which will only work for a very narrow range of devices and actually might result in increased uncertainty in test houses, where the device parameters and state are not known. This, however, requires the knowledge of the voltage dependent spectral response of a test device, which is not a simple task to measure, together with the knowledge of the time resolved spectrum in the solar simulator, which is also hard to quantify accurately.

\section{Acknowledgements}

The authors wish to acknowledge the financial support of the Engineering and Physical Sciences Research Council (EPSRC) of the United Kingdom through the EPSRC grant Nos GR/T03307/01 and GR/T03314/01. The kind assistance of Professor Marc Burgelman (ELIS, University of Ghent) is also gratefully acknowledged. The authors would also like to thank Professor Christophe Ballif and Dr. Martin Python of PV$\mathrm{LAB}, \mathrm{EPFL}$ for the helpful discussions and the contribution of data for the validation of the model.

\section{References}

[1] ASTM 1999, Standard test method for calibration of primary non-concentrator terrestrial photovoltaic reference cells using a tabular spectrum ASTM E 1125-99 [2] IEC 60904-3 Photovoltaic devices. Part 3: Measurement principles for terrestrial photovoltaic (PV) solar devices with reference spectral irradiance data

[3] ASTM 2005, Standard Specification for Solar Simulation for Photovoltaic Testing, ASTM E 927-05

[4] IEC 60904-7 Photovoltaic devices. Part 7: Computation of spectral mismatch error introduced in the testing of a photovoltaic device

\footnotetext{
${ }^{2}$ The word calibration is used in the industrial sense, where this stands for introducing correction factors rather than ensuring traceability to SI units.
} 
[5] J. Bruns, S. Gall, H.G. Wagemann, 22nd IEEE PVSC, (1991); pp.1323-1328. [6] R. Rüther, G. Kleiss, K. Reiche, Solar Energy Materials \& Solar Cells, Vol. 71 (2002); pp. 375-385.

[7] S. Kohraku, K. Kurokawa, Procs. of $3^{\text {rd }}$ World Conference on Photovoltaic Energy Conversion, IEEE, Cat. no. 03CH37497 (2003); pp.1977-1980.

[8] R. Grischke, J. Schmidt, H. Albert, A. Laux, A. Metz, U.Hilsenberg, J.Gentischer, $19^{\text {th }}$ EU PVSEC, 2 (2004); pp.2591-2594.

[9] M. Bliss, T.R. Betts, R. Gottschalg, Solar Energy Materials \& Solar Cells (2008), doi:10.1016/j.solmat.2008.09.056.

[10] D.L. Staebler and C.R. Wronski, Appl. Phys. Lett., Vol. 31, Is. 4, (1977); pp. 292 294.

[11] J.A. del Cueto, B. von Roedern, Prog. Photovolt: Res. Appl., Vol. 7 (1999); pp 101-112

[12] C. Monokroussos, Ph.D. Thesis, Loughborough University, July 2010 (submitted)

[13] G.H. Spencer, M.V.R.K. Murty, J. Opt. Soc. Am., Vol. 52, Num. 6 (1962); pp.

672-678, doi:10.1364/JOSA.52.000672

[14] J.S.C. Prentice, J. Phys. D: Appl. Phys., Vol. 32 (1999); pp. 2146-2150.

[15] J. Krč, F. Smole, M. Topič, J. Appl. Phys., Vol. 92, Is. 2 (2002); 749-755.

[16] J. Springer, A. Poruba, M. Vanecek, J. Appl. Phys., Is. 96, Num. 9 (2004); pp. 5329-5337.

[17] P. Beckmann, A. Spizzichino, Scattering of Electromagnetic Waves from Rough Surfaces, New York, NY: Artech House Publishers, ISBN 0-89006-238-2 (1987). [18] S. Selberherr, Analysis and Simulation of Semiconductor Devices, SpringerVerlag (1984).

[19] D.L. Schrafetter and H.K. Gummel, IEEE Trans. Electron Devices, ED-16, 1969; p. 64.

[20] M. Burgelman, P. Nollet, S. Degrave, Thin Solid Films, 361-362 (2000); pp. 527-532

[21] J.Hubin, A.V.Shah, E. Sauvain, Philosophical Magazine Letters, Vol. 66 (1992); p. 115.

[22] M.Hack, M.Shur, J.Appl.Phys., Vol. 58, Num. 2 (1985); pp.997-1020.

[23] S.M. Sze, Semiconductor Devices: Physics and Technology, 2nd edition, John Wiley \& Sons, Inc. (2002).

[24] S. Olibet, E. Vallat-Sauvain, C. Ballif, Physical Review B 76, 035326 (2007). [25] A. Allag, T. Smaïl, M. Aoucher, Journal of Non-Crystalline Solids, Vol. 352 (2006); pp. 1184-1187.

[26] L. Yang, L. Chen, Journal of Non-Crystalline Solids, Vol. 137-138 (1991); pp. 1189-1192

[27] P. Vorasayan, T.R. Betts, R. Gottschalg, A.N. Tiwari, Proceedings of the 15th Photovoltaic Science \& Engineering Conference, Shanghai (2005)

[28] P A. Fantoni, M. Viera, R. Martins, Solar Energy Materials and Solar Cells, Vol. 73, Is. 2 (2002); pp. 151-162

[29] IEC 60904-8 Photovoltaic devices. Part 8: Measurement of spectral response of a photovoltaic (PV) device

[30] IEC 60904-9 Photovoltaic devices. Part 9: Solar simulator performance requirements

[31] T.R. Betts, R. Gottschalg, Procs. of Photovoltaic Applications, Science and Technology (PVSAT-2) (2005). 
[32] R. Gottschalg, T.R. Betts, J. Hohl-Ebinger, W. Herrmann, H. Müllejans, 22nd EU PVSEC, Milan, (2007); pp. 2621-2624

[33] R. Gottschalg, T.R. Betts, D.G. Infield, M.J. Kearney, Solar Energy Materials \& Solar Cells, Vol. 85 (2005); pp. 415-428

[34] T. Minemoto, Y. Nakada, H. Takahashi, H. Takakura, Solar Energy (2009), doi:10.1016/j.solener.2009.03.004.

[35] J. Bruns, Ph.D. Thesis, Technische Universität, Berlin, 1993.

[36] H. Field, K. Emery, 19th IEEE PVSC (1985), pp. 153-159.

[37] C. J. Hibberd, F. Plyta, C. Monokroussos, M. Bliss, T.R. Betts, R. Gottschalg, Solar Energy Materials \& Solar Cells, doi: 10.1016/j.solmat.2010.03.039 